\title{
Synthesis and Characterization of Novel Polyesters and Polyurethanes Containing 9,10-Diethynylanthracene and Pyromellitic Diimide
}

\author{
Sergei Fomine, ${ }^{\dagger}$ Margarita Marin, Lioudmila Fomina, Roberto Salcedo, Enrique Sansores, \\ Juan Manuel Mendez, Cristina Flores Jimenez, ${ }^{*}$ and Takeshi Ogawa \\ Instituto de Investigaciones en Materiales Universidad Nacional Autonoma de Mexico, \\ Apartado Postal 70-360, Coyoacan, Mexico DF, 04510 \\ * Instituto de Fisica Universidad Nacional Autonoma de Mexico, \\ Apartado Postal 20-364, Coyoacan, Mexico DF, 01000
}

(Received October 20, 1995)

\begin{abstract}
A Novel monomer 9,10-bis(4-hydroxy-1-butynyl)anthracene (M1) was synthesized and some polyesters and polyurethanes containing a donor 9,10-diethynylanthracene and acceptor pyromellitic diimide groups were prepared. The polymers were soluble in common organic solvents and gave transparent films by casting. They showed $5 \%$ weight loss at the temperature $250-300^{\circ} \mathrm{C}$. All polymers showed luminescence and maximum depended on polymer composition. Polymers containing the 9,10-diethynylanthracene moiety alone showed luminescence with maximum at $470-480 \mathrm{~nm}$ while those containing 9,10-diethynylanthracene and pyromellitic diimide groups showed luminescence with maximum around $600 \mathrm{~nm}$ due to the charge transfer complex (CTC) formation between them. Some polymers showed electroluminescence with turn-on voltage of $10.5 \mathrm{~V}$.

KEY WORDS Polyesters / Polyurethanes / Polyimides / Luminescence / Electroluminescence / 9,10-Diethynylanthracene /
\end{abstract}

Various fluorescent polymers have been investigated in recent years. These polymers include pendent chromophore-functionalized polymers and polymers having chromophore in the backbone. They are used as fluorescent labels, and photon harvesters. ${ }^{1-3}$ Fluorescent labeling has been used to study specific interactions between macromolecules in water soluble polymers, polyelectrolytes, block copolymers, homopolymers, and random copolymers ${ }^{4-9}$ water soluble polymers with aromatic chromophores sensitize photochemical reactions. ${ }^{10}$

Novel polymers containing fluorescein moieties were prepared recently at our laboratory. ${ }^{11,12}$ They were soluble in common solvents and gave films with excellent transparency when casted from solutions. The polymers showed intense yellow luminescence in solutions and as films, and exhibited non-linear optical susceptibility of the third order $\left(\chi^{(3)}\right)$ up to $3 \times 10^{-10}$ esu. A number of novel polymers containing arylenevinylideneethynylene groups was also synthesized via the Heck reaction. ${ }^{13}$ The polymers were amorphous and soluble in common organic solvents. Some showed strong blue luminescence in the region of $380-480 \mathrm{~nm}$. All polymers showed $\left(\chi^{(3)}\right)$ around $10^{-10}$ esu.

Another interesting class of photoactive polymers is anthracene containing polymers. They show intense blue fluorescence and photoconductive properties. ${ }^{14}$ Various vinyl type anthracene-containing polymers have been prepared. ${ }^{15}$ However, only a few papers report on the synthesis of polycondensation type polymers containing anthracene moieties. The synthesis and luminescence properties of some anthracene contained polyimides derived from 9,10-bis(3-aminophenylthio)anthracene, and 9,10-bis-(3-amino-4-methoxybenzyl)anthracene with various tetracarboxylic acid dianhy-

\footnotetext{
† To whom correspondence should be addressed.
}

drides, have been reported. ${ }^{16,17}$ All the polymers showed luminescence and photoconductive properties and the position of the maximum of luminescence was linear with electron affinity of diimide fragment due to the excited state of CTC formation between anthracene and imide moieties. Absorption bands in polyimide consisting of pyromellitic acid and 4,4'-diaminodiphenylether moieties are due to intermolecular charge transfer $\pi-\pi^{*}$ transitions. ${ }^{18}$

This paper reports the first synthesis and characterization of donor-acceptor types of polymers containing 9,10-diethynylanthracene moiety as a donor, based on novel monomer, 9,10-bis-(4-hydroxy-1-butynyl)anthracene. A facile one-step synthesis of this monomer has been developed starting from commercially available 9,10-dibromoanthracene and 3-butyl-1-ol. 9,10-Diethynylanthracene chromophore should possess a lower ionization potential and higher electron affinity than anthracene due to the conjugation of two additional triple bonds with an anthracene fragment while maintaining high photoluminescence efficiency of anthracene because of the rigidity of 9,10-diethynylanthracene moiety. The expanded conjugation system of 9,10-diethynylanthracene should provide the polymers with novel interesting optical properties compared to anthracene, such as low turn-on voltage of electroluminescence, in particular.

\section{EXPERIMENTAL}

\section{Materials}

1,2-Dichlorobenzene (ODCB), dimethyl sulfoxide (DMSO), hexamethylene diisocyanate, sebacoyl chlorides, and isophthaloyl chlorides were distilled under reduced pressure before use. Pyromellitic dianhydride was crystallized from acetic anhydride. Other reagents (all Aldrich) were used as received. 


\section{Monomer Synthesis}

The synthesis of the monomers is shown in Scheme 1. 9,10-Dibromoanthracene was prepared by the bromination of anthracene in chloroform. $T_{\mathrm{m}}=225^{\circ} \mathrm{C}\left(224^{\circ} \mathrm{C}^{19}\right)$.

9,10-Bis-(4-hydroxyl-1-butynyl)anthracene (M1). 9,10Dibromoanthracene $(16.8 \mathrm{~g}, 50 \mathrm{mmol}), 3$-butyn-1-ol $(14 \mathrm{~g}, 200 \mathrm{mmol})$, triphenylphosphine (TPP $(0.5 \mathrm{~g}, 1.9$ $\mathrm{mmol}), \mathrm{CuI}(0.3 \mathrm{~g}, 1.57 \mathrm{mmol})$, and $\mathrm{PdCl}_{2}(\mathrm{TPP})_{2}(0.5 \mathrm{~g}$, $0.71 \mathrm{mmol}$ ) were dissolved in a mixture of pyridine $(200 \mathrm{ml})$ and triethylamine $(200 \mathrm{ml})$ and refluxed for $6 \mathrm{~h}$ under nitrogen flow. The reaction mixture was poured in cold diluted hydrochloric acid and precipitate formed was filtered off and dried in vacuo at room temperature. The crude product was purified by column chromatography on $\mathrm{SiO}_{2}$ (eluent benzene) Yield $68 \%, T_{\mathrm{m}}=$ $168^{\circ} \mathrm{C}$. IR ( $\left.\mathrm{cm}^{-1}\right): 3285(\mathrm{OH}), 3057$ (CH arom.), 2930 2880 ( $\mathrm{CH}$ aliph.), $2200 \quad(\mathrm{C} \equiv \mathrm{C}), 1618,1520 \quad(\mathrm{C}=\mathrm{C}$ arom.). ${ }^{1} \mathrm{H}$ NMR (DMSO- $\left.d_{6}\right): 8.62-8.59(\mathrm{~m}, 4 \mathrm{H}$, arom.), $7.64-7.61(\mathrm{~m}, 4 \mathrm{H}$, arom.), $4.15(\mathrm{t}, 2 \mathrm{H},-\mathrm{OH}$, $J=6.0 \mathrm{~Hz}), 4.00-3.94\left(\mathrm{~m}, 4 \mathrm{H}, \mathrm{O}-\mathrm{CH}_{2}\right), 2.99(\mathrm{t}, 4 \mathrm{H}$, $\left.\equiv \mathrm{C}-\mathrm{CH}_{2} \quad J=7.5 \mathrm{~Hz}\right) .{ }^{13} \mathrm{C}$ NMR (DMSO- $\left.d_{6}\right): 132.9$, $128.0,127.5,119.4$ (arom.), 104.4, 78.5 (C $\equiv \mathrm{C}), 61.7$ $\left(\mathrm{O}-\mathrm{CH}_{2}\right), 25.1\left(-\mathrm{CH}_{2}-\mathrm{C} \equiv\right)$.

$N, N^{\prime}$-Bis(3-hydroxy-n-propyl)pyromellitic diimide (M2). Pyromellitic dianhydride $(21.8 \mathrm{~g}, 100 \mathrm{mmol}) 3-$ aminopropanol $(18.75 \mathrm{~g}, 250 \mathrm{mmol})$ and ODCB $(500 \mathrm{ml})$ were heated to reflux. The reaction mixture was slowly distilled during $3 \mathrm{~h}$ until the volume was reduced to $200 \mathrm{ml}$. The reaction solution was cooled to room temperature and the precipitate was filtered off. The crude product was crystallized from ODCB and dried in vacuo.
Yield $88 \% . T_{\mathrm{m}}=240^{\circ} \mathrm{C}$. IR $\left(\mathrm{cm}^{-1}\right): 3285(\mathrm{OH}), 3050$ (CH arom.), 2970-2890 ( $\mathrm{CH}$ aliph.), 1776, $1720(\mathrm{C}=\mathrm{O}$, imide). ${ }^{1} \mathrm{H}$ NMR (DMSO- $\left.d_{6}\right): 8.15$ (s, 2H, arom.), 4.44 $(\mathrm{t}, 2 \mathrm{H},-\mathrm{OH} J=5.2 \mathrm{~Hz}), 3.73\left(\mathrm{t}, 4 \mathrm{H},>\mathrm{N}-\mathrm{CH}_{2}-J=\right.$ $7.7 \mathrm{~Hz}), 3.51-3.42\left(\mathrm{~m}, 4 \mathrm{H},-\mathrm{O}-\mathrm{CH}_{2}\right), 18.2-1.73(\mathrm{~m}$, $4 \mathrm{H},-\mathrm{C}-\mathrm{CH}_{2}-\mathrm{C}-$ ). ${ }^{13} \mathrm{C}$ NMR (DMSO- $\left.d_{6}\right)$ : $166.1(\mathrm{C}=\mathrm{O}$, imide) 136.9116 .9 (arom.), $58.49\left(\mathrm{O}-\mathrm{CH}_{2}-\right), 35.72$ $\left(>\mathrm{N}-\mathrm{CH}_{2}-\right), 30.83\left(-\mathrm{CH}_{2}-\mathrm{CH}_{2}-\mathrm{CH}_{2}-\right)$.

\section{Polymerisation}

Polymer synthesis is shown in Scheme 2.

Polyester PE1, PE2, and PE3. Monomer M1, M2, or their mixture $(2 \mathrm{mmol})$ and ODCB $(5 \mathrm{ml})$ was heated to $100^{\circ} \mathrm{C}$ under nitrogen flow and cooled down. Sebacoyl or isophthaloyl chloride $(2.02 \mathrm{mmol})$ were added to the mixture and the solution temperature was raised to $140^{\circ} \mathrm{C}$. Then the reaction was followed by FT-IR spectroscopy until the absorption band of acid chloride carbonyl $\left(1780 \mathrm{~cm}^{-1}\right)$ completely disappeared. The reaction mixture was poured in methanol and the polymer precipitated was filtered off, washed with methanol and dried in vacuo at room temperature.

Polyurethanes PU1 and PU2. Monomer M1, M2 or their mixture $(2 \mathrm{mmol})$ and DMSO $(5 \mathrm{ml})$ were heated to $100^{\circ} \mathrm{C}$ under nitrogen flow and cooled down. Hexamethylene diisocyanate $(2 \mathrm{mmol})$ was added to the mixture and the solution temperature was raised to $150^{\circ} \mathrm{C}$ during $2 \mathrm{~h}$ under nitrogen flow and maintained at this level until the absorption band of isocyanate at $2260 \mathrm{~cm}^{-1}$ completely disappeared. Then the reaction mixture was poured in methanol; the polymer precipitated was fitered off, washed with methanol and dried
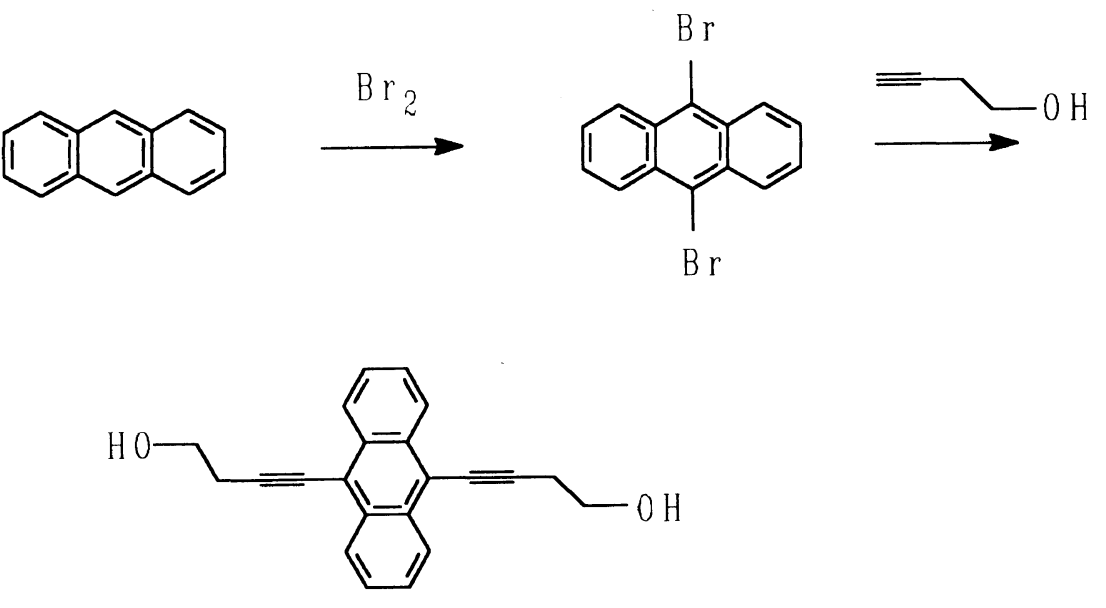

M 1<smiles>NCCCO</smiles><smiles>O=c1c2cc3c(=O)n(CCCO)c(=O)c3cc2c(=O)n1CCCO</smiles>

M 2 

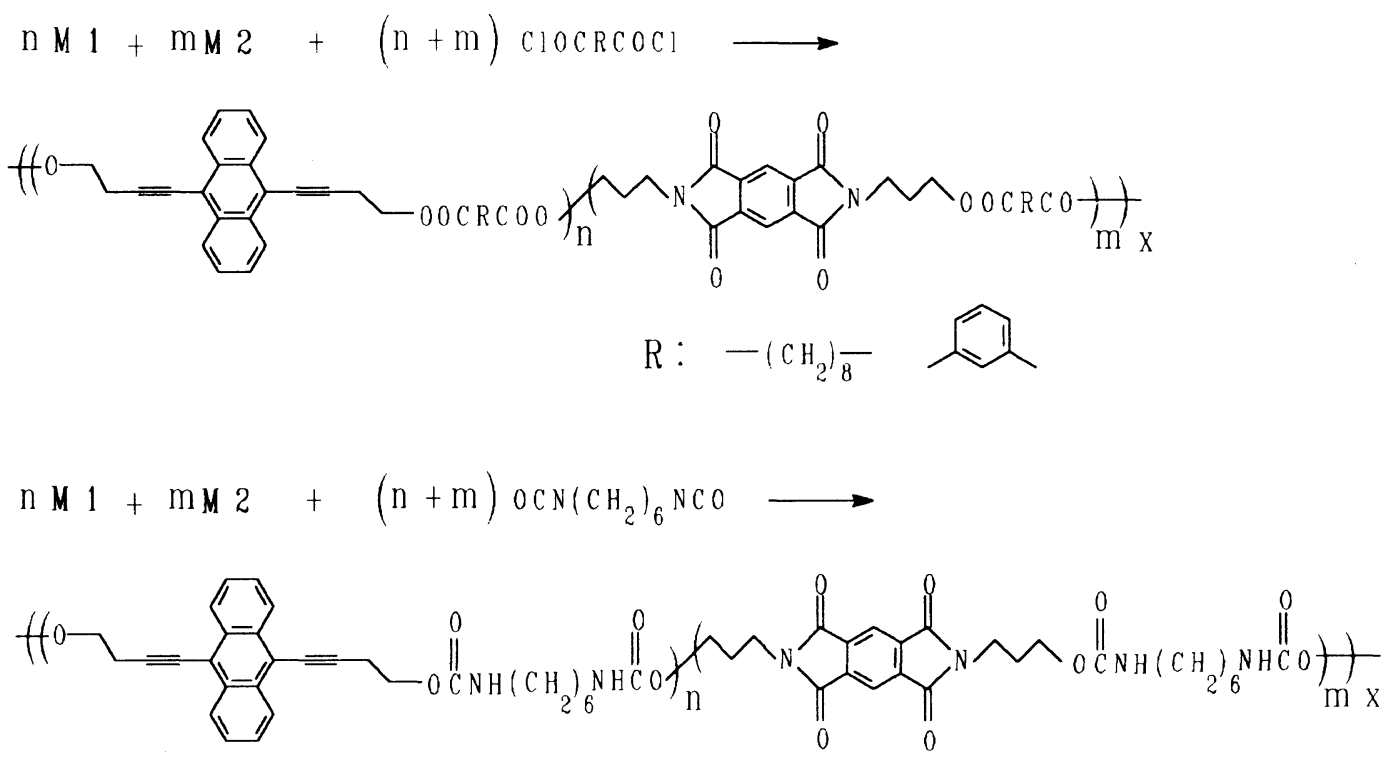

\begin{tabular}{|c|c|c|c|c|}
\hline \multicolumn{5}{|c|}{ Polyesters } \\
\hline Polymer & $R$ & $n$ & $m$ & Yield \\
\hline PE1 & $-\left(\mathrm{CH}_{2}\right)_{8}-$ & 1 & 0 & 93 \\
\hline PE2 & 1,3-Ph & 1 & 0 & 95 \\
\hline PE3 & $1,3-\mathrm{Ph}$ & 0.5 & 0.5 & 91 \\
\hline \multicolumn{5}{|c|}{ Polyurethanes } \\
\hline PU1 & & 1 & 0 & 98 \\
\hline PU2 & & 0.5 & 0.5 & 97 \\
\hline
\end{tabular}

Scheme 2.

in vacuo at room temperature.

PE1: IR ( $\left.\mathrm{cm}^{-1}\right)$ : 3080 (C-H arom.), 2970-2890 (C-H aliph.), $2210(\mathrm{C} \equiv \mathrm{C}), 1730(\mathrm{C}=\mathrm{O}$, ester $), 1620(\mathrm{C}=\mathrm{C}$ arom). ${ }^{13} \mathrm{C}$ NMR (ppm) $\left(\mathrm{CDCl}_{3}\right): 173(\mathrm{C}=\mathrm{O}$ ester $)$, $133,128,127,119$ (arom.), 100, $79(\mathrm{C} \equiv \mathrm{C}), 61\left(\mathrm{OCH}_{2}{ }^{-}\right)$, 34, 29, 24 (aliph), 20 ( $\left.\equiv \mathrm{C}-\mathrm{CH}_{2}\right)$.

PE2: IR (cm $\left.{ }^{-1}\right)$ : 3050 (C-H arom.), $2950-2900$ (C-H aliph.), $2210(\mathrm{C} \equiv \mathrm{C}), 1730(\mathrm{C}=\mathrm{O}$, ester $), 1610(\mathrm{C}=\mathrm{C}$ arom). ${ }^{13} \mathrm{C} \mathrm{NMR}(\mathrm{ppm})\left(\mathrm{CDCl}_{3}\right): 166(\mathrm{C}=\mathrm{O}$ ester $), 139$, 128, 127, 119 (arom. anthracene), 134, 131, 130, 129.5 (arom. benzene), 102, $79(\mathrm{C} \equiv \mathrm{C}), 61\left(\mathrm{OCH}_{2}-\right), 20$ ( $\equiv \mathrm{C}-$ $\mathrm{CH}_{2}$ ).

PE3: IR ( $\left.\mathrm{cm}^{-1}\right)$ : 3080 (C-H arom.), 2950-2900 (C-H aliph.), $2210(\mathrm{C} \equiv \mathrm{C}), 1780,1730(\mathrm{C}=\mathrm{O}$, ester and imide $)$, 1610 (C=C arom.). ${ }^{13} \mathrm{C}$ NMR (ppm) $\left(\mathrm{CDCl}_{3}\right)$ : 166.5 ( $\mathrm{C}=\mathrm{O}$, imide), 166 ( $\mathrm{C}=\mathrm{O}$ ester $), 133,128,127,119$ (arom. anthracene), 134, 131, 130, 129.5 (arom. isophtalic), 137, 117 (arom. pyromellitic), 102, 79 (C $\equiv \mathrm{C})$, $61\left(\mathrm{OCH}_{2}-\right), 20\left(\equiv \mathrm{C}-\mathrm{CH}_{2}\right)$.

PUl: IR $\left(\mathrm{cm}^{-1}\right)$ : $3400(\mathrm{~N}-\mathrm{H}$ urethane), $3060(\mathrm{C}-\mathrm{H}$ arom.), 2950-2850 (C-H aliph.), 2220 (C $\equiv \mathrm{C}), 1720$ (C=O, urethane), 1610 (C=C arom.). ${ }^{13} \mathrm{C}$ NMR (ppm) $\left(\mathrm{DMSO}-d_{6}\right): 156(\mathrm{C}=\mathrm{O}$, urethane $), 133,128,127,119$

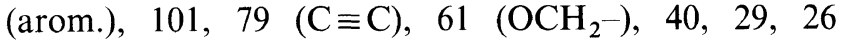
(hexamethylene spacer), $20\left(\equiv \mathrm{C}-\mathrm{CH}_{2}\right)$.

PU2: IR $\left(\mathrm{cm}^{-1}\right)$ : $3400(\mathrm{~N}-\mathrm{H}$ urethane) $3060(\mathrm{C}-\mathrm{H}$ arom.), 295-2850 (C-H aliph.), 2220 (C $\equiv \mathrm{C}), 1720$ ( $\mathrm{C}=\mathrm{O}$, urethane), 1610 ( $\mathrm{C}=\mathrm{C}$ arom.). ${ }^{13} \mathrm{C} \mathrm{NMR}$ (ppm) (DMSO- $\left.d_{6}\right): 166(\mathrm{C}=\mathrm{O}$, imide), $156(\mathrm{C}=\mathrm{O}$, urethane),
133, 128, 127, 119 (arom. anthracene), 137, 117 (arom. pyromellitic), 101, $79(\mathrm{C} \equiv \mathrm{C}), 61\left(\mathrm{OCH}_{2}-\right), 40,29,26$ (hexamethylene spacer), 58, 36, 30 (trimethylene spacer), $20\left(\equiv \mathrm{C}-\mathrm{CH}_{2}\right)$.

\section{Measurements and Sample Preparation}

The relative molecular weights of polymers PE1, PE2, and PE3 were determined using Varian 9012 GPC instrument at $30^{\circ} \mathrm{C}$ in $\mathrm{CH}_{2} \mathrm{Cl}_{2}$ with the polystyrene standard, universal column, and flow of $1 \mathrm{ml} \mathrm{min}^{-1}$. Inherent viscosity was measured $0.5 \mathrm{wt} \%$ solution in $N$-methylpyrrolidone (NMP) (PU1 and PU2). DSC and TGA were performed at a heating rate of 10 and $5^{\circ} \mathrm{Cmin}{ }^{-1}$, respectively under nitrogen with a du Pont 2100 machine. FT-IR-spectra were taken using a Nikolett 510p spectrometer. UV-visible spectra were taken using a Shimadzu UV-260 spectrometer in chloroform or in films spin coated onto quartz plates. ${ }^{1} \mathrm{H}$ NMR and ${ }^{13} \mathrm{C}$ NMR spectra were taken using a Varian spectrometer at $300 \mathrm{MHz}$ and $75.5 \mathrm{MHz}$, respectively, in $\mathrm{CDCl}_{3}$ or DMSO- $d_{6}$ with tetramethylsilane (TMS) as the internal standard. Photoluminescence was measured using a Perkin-Elmer $630-10 \mathrm{~S}$ fluorimeter in $\mathrm{CHCl}_{3}$ for polyesters and in $N$-methylpyrrolidone (NMP) for polyurethanes solution or in solid films with excitation wavelength of $300 \mathrm{~nm}$. Excitation spectra of the polymers were measured with emission wavelength of $420 \mathrm{~nm}$. 


\section{RESULTS AND DISCUSSION}

All polyesters were soluble in chlorinated solvents such as chloroform, dichloromethane, or ODCB and gave optically transparent films with strong luminescence when casted. The molecular weights of the polymers $\left(M_{w}\right)$ found by GPC were of 18000,21000 , and 16500 for PE1, PE2, and PE3, respectively, with polydispersity index of around 3.5. According to X-ray diffraction data, the polyesters were generally amorphous with crystallinity of 14,6 , and $6 \%$ for polymers PE1, PE2, and PE3, respectively. The relatively high crystallinity of PE1 compared to the others reflects the presence of long octamethylene spacer which makes it easier for the polymer chains of PE1 to be ordered.

DSC curves of polymers PE1, PE2, and PE3 are shown in Figure 1. PE1 exhibited a glass transition at $75^{\circ} \mathrm{C}$,
PE2 at $65^{\circ} \mathrm{C}$, and PE3 at $172^{\circ} \mathrm{C}$. A large difference between the glass transition temperature of PE1, PE2, and PE3 is due to the presence of mide moieties in the latter. All polymers showed exotherm peak with maxima around $250^{\circ} \mathrm{C}$ due to the thermal cross-linking of the triple bonds (IR spectra of the polymers showed no absorption band at $2210 \mathrm{~cm}^{-1}$ after such thermal treatment and the polymers lost their solubility). According to TGA data polymers PE1, PE2, and PE3 showed 5\% weight loss at 300,280 , and $250^{\circ} \mathrm{C}$, respectively.

Figure 2 shows UV-Visible absorption, emission and excitation spectra of films of polymers PE1 and PE3. The absoption and emission spectra of PE2 are similar to those of PE1 and not shown in the Figure 2. Both spectra exhibit a characteristic band of 9,10-diethynylanthracene moiety in the range of $435-250 \mathrm{~nm}$. PE3 Shows an additional weak shoulder with a maximum

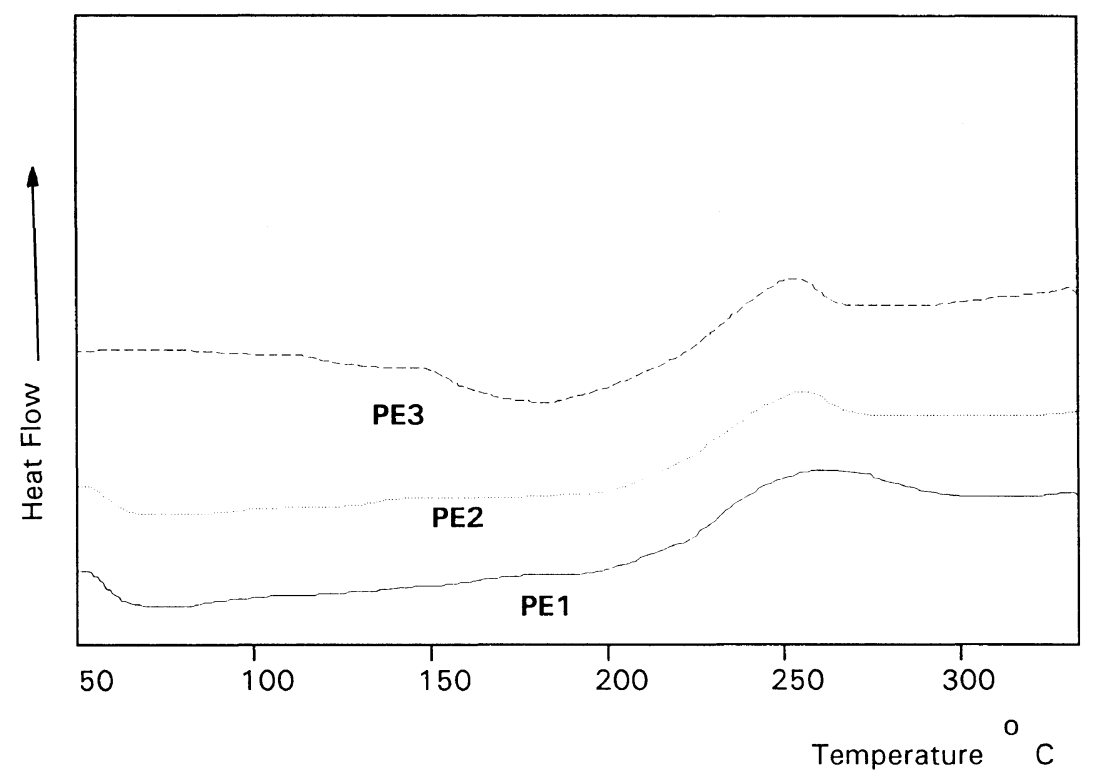

Figure 1. DSC curves of polymers PE1, PE2, and PE3.

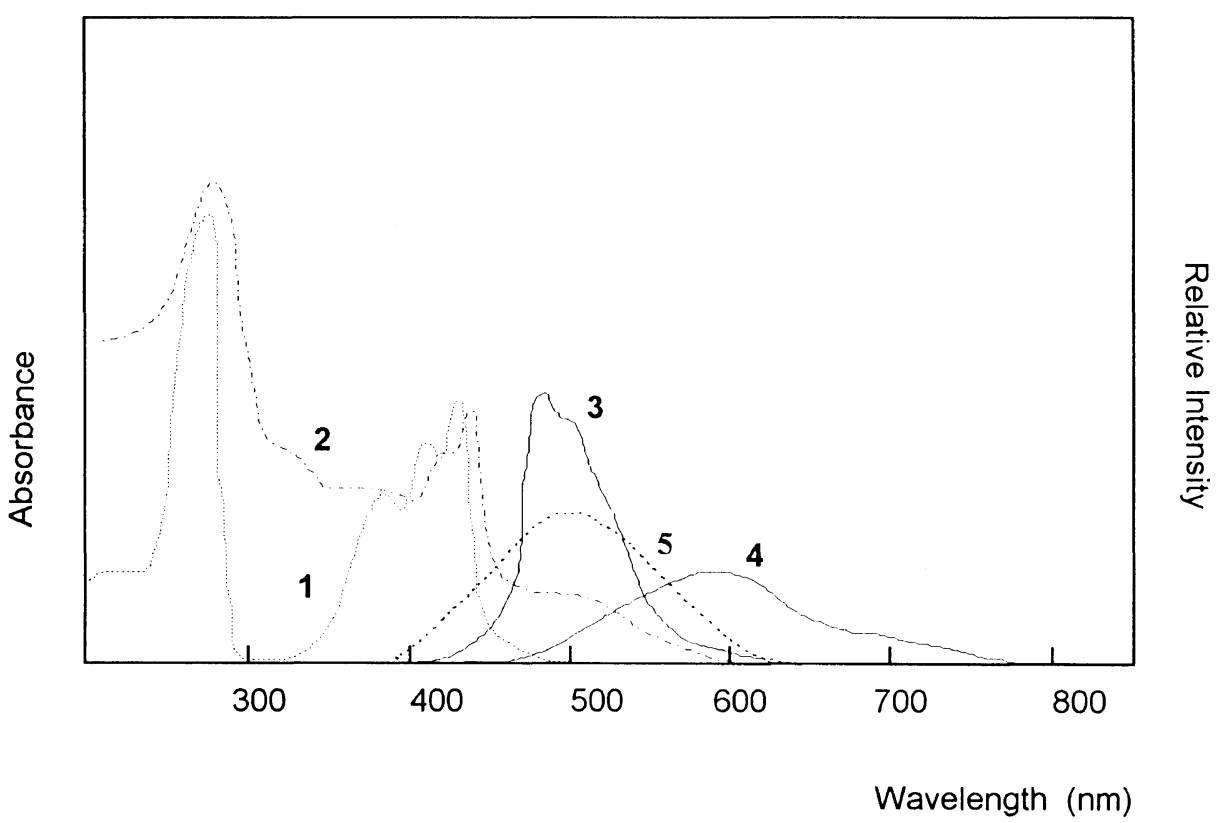

Figure 2. Absorption (1 and 2) and emission (3 and 4) $\left(\lambda_{\mathrm{ex}}=300 \mathrm{~nm}\right)$ spectra of films of polymers PE1 and PE3, respectively, and excitation spectrum of PE3 (5) $\left(\lambda_{\mathrm{em}}=420 \mathrm{~nm}\right)$. 
around $510 \mathrm{~nm}$. This absorption can be explained by charge transfer complex (CTC) formation of donor 9,10-diethynylanthracene moiety with the acceptor pyromellitic diimide fragment. This was proven by emission and excitation spectra of the polymers. Polymers PE1 and PE2 showed emission spectra with maxima around $470-480 \mathrm{~nm}$, while PE3 exhibited fluorescence with a maximum at $600 \mathrm{~nm}$ and a maximum at $508 \mathrm{~nm}$ in the excitation spectrum. This means that in the case of PE1 and PE2, excited 9,10-diethynylanthracene moieties are light emitting units while in the case of PE3 the existed CTC states are responsible for fluorescence. The bathofluoric shift of the fluorescence maximum for PE3 is due to the smaller difference in energy between the highest occupied and lowest unoccupied molecular orbitals (HOMO and LUMO, respectively) in CTC compared to the 9,10-diethynylanthracene unit alone. It is noteworthy that $\mathrm{CT}$ absorption and emission bands were observed only in films. In solution the emission spectra of all polymers were identical to PE1. This means that CTC formation takes place only in the solid state not in solution.

Polymers PU1 and PU2 were soluble in NMP and DMSO and showed inherent viscosities of 0.49 and $0.61 \mathrm{dlg}^{-1}$ respectively. The former gave an opaque cast-film when cast while the latter gave a film of good optical quality. According to X-ray diffraction data PU1 was semicrystalline with crystallinity of $12 \%$ whereas PU2 was almost totally amorphous. This difference is due to the fact that PU2 is a random copolymer.

DCS curves of polymers PU1 and PU2 are shown in Figure 3. Both showed a glass transition around $100^{\circ} \mathrm{C}$ and an exotherm peak with the maximum at $250^{\circ} \mathrm{C}$ due to the thermal cross-linking of the triple bonds. According to TGA data, the polymers lost $5 \%$ of their weight on heating to $150^{\circ} \mathrm{C}$ due to evaporation of

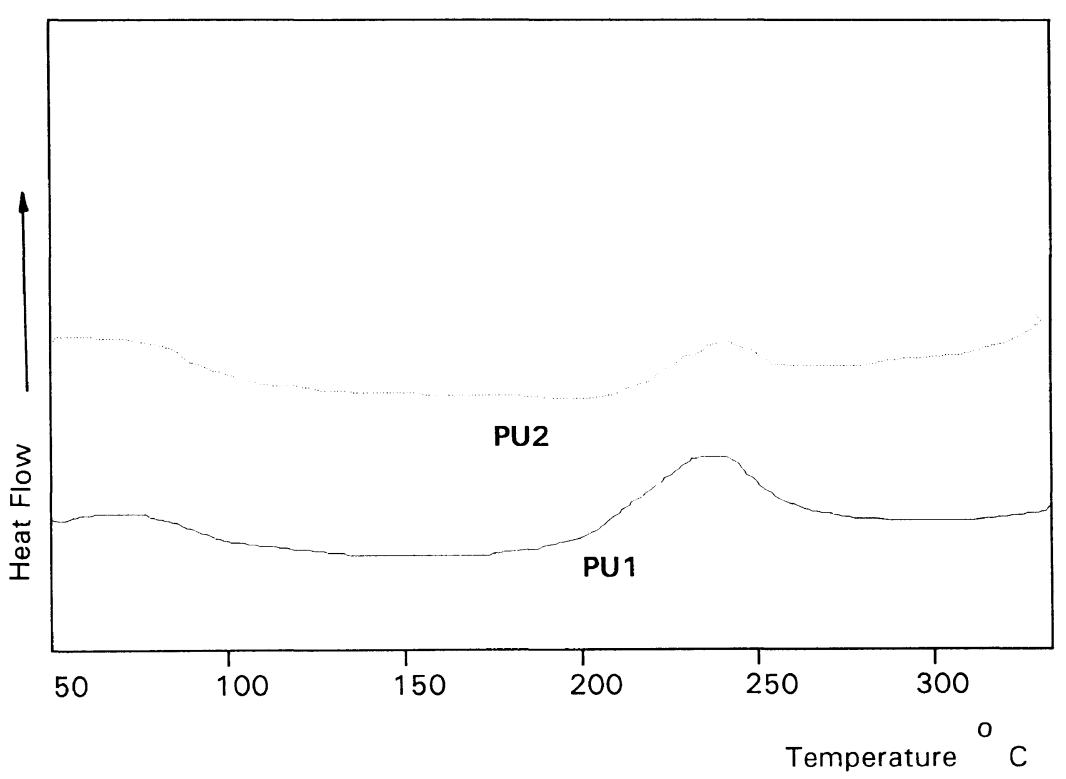

Figure 3. DSC curves of polymers PU1 and PU2.

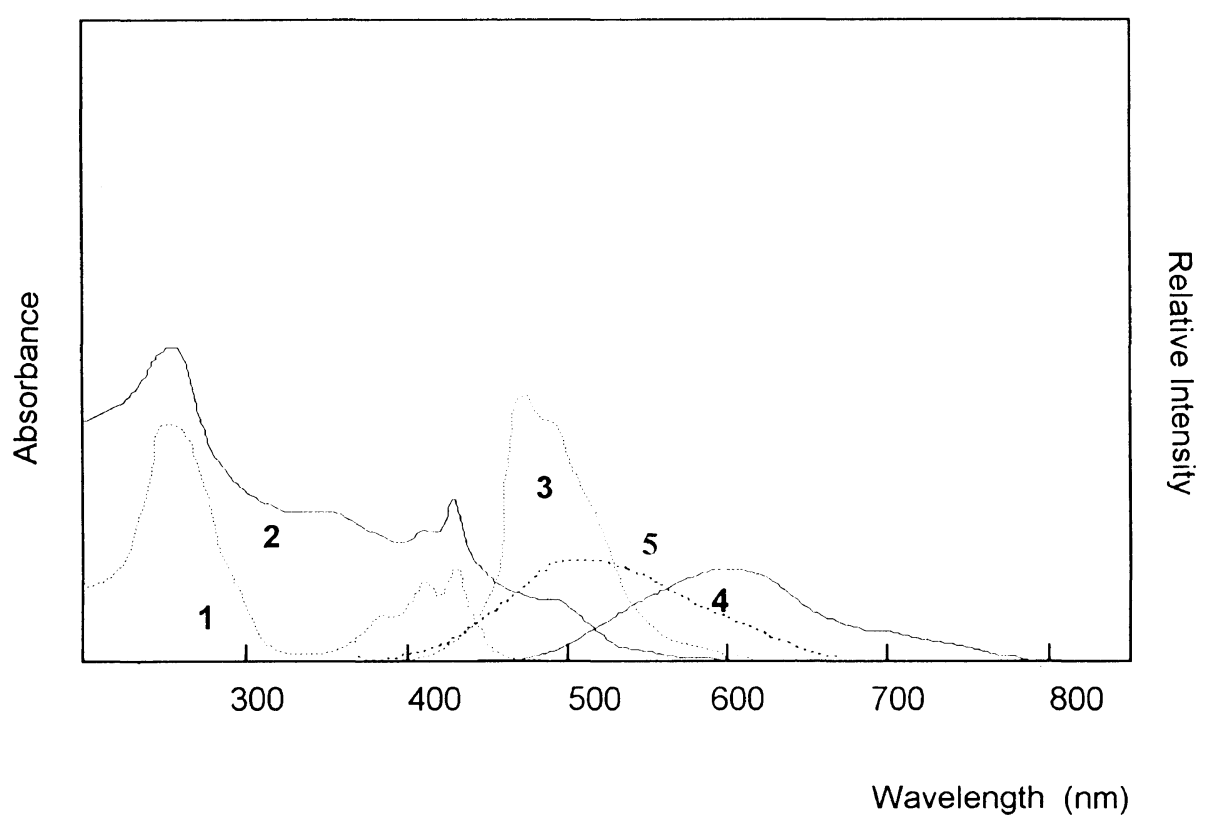

Figure 4. Absorption (1 and 2) and emission (3 and 4) $\left(\lambda_{\mathrm{ex}}=300 \mathrm{~nm}\right)$ spectra of films of polymers PU1 and PU2, respectively, and excitation spectrum of PE2 (5) $\left(\lambda_{\mathrm{em}}=420 \mathrm{~nm}\right)$. 
absorbed water and traces of DMSO used as solvent for the polycondensation. The polymers maintained their weight on heating to $280^{\circ} \mathrm{C}$ where the thermal decomposition started.

UV-Visible abosrption, emission and excitation spectra of the films of polymers PU1 and PU2 are presented in Figure 4. As can be seen from the figure, the absorption and emission spectra of polymers PU1 and PU2 are similar to those of PE1 and PE3, respectively. The CTC band can be seen in the absorption spectra of the PU2 around $500 \mathrm{~nm}$ and the emission spectra of PU2 suffers a bathofluoric shift of about $120 \mathrm{~nm}$ as compared to that of PU1 due to the luminescence from the existed CTC in PU2 which also proved by the maximum at $505 \mathrm{~nm}$ in the excitation spectrum of PU2.

An electroluminescent device with PE3 has been made. The device consists of ITO coated glass, CuPc $(20 \mathrm{~nm}$ evaporated), PE3 (dissolved in chloroform and spincasted for thickness $50 \mathrm{~nm}$ ), and $\mathrm{Ca}$ ( $100 \mathrm{~nm}$ evaporated). After the PE3 layer was spun the film was baked for $16 \mathrm{~h}$ at $70^{\circ} \mathrm{C}$ to drive off the solvent. This device showed diode behavior and emitted light with turn-on voltage of about $10.5 \mathrm{~V}$, which is reasonably low. The spectra of electroluminescence were similar to the emission spectra of the polymer, suggesting that the nature of the emitting units was essentially the same in both cases (exited CTC). The internal efficiency of electroluminescence was low, reaching only $0.002 \%$.

The polymers prepared in this article showed differences from those synthesized previously. ${ }^{16,17}$ The first one is a long wave shift of the long wave absorption maximum by $30-40 \mathrm{~nm}$ due to expanding of the conjugated system in 9,10-diethynylanthracene moiety as compared to anthracene. The second is increase in donor-acceptor interaction in polymers PE1, PE2, PE3, PU1, and PU2 as compared with those synthesized previously. Thus, polymers containing pyromellitic diimide and anthracene moieties exhibited no CT absorption band in the absorption spectra. ${ }^{16}$ This difference can be explained by the expanded conjugation system in 9,10-diethynylanthracene moiety which makes its ionization potential lower. The third is that polymers synthesized previously ${ }^{16}$ showed no measurable electroluminescence while PE3 exhibited electroluminescence with turn-on voltage of $10.5 \mathrm{~V}$. This difference is probably due to the stronger donor-acceptor interaction in the latter which makes charge separation easier.

However, the triple bonds in the polymers showed decrease of thermal stability. Thus, all polymers containing 9,10-diethynylanthracene moiety underwent thermal crosslinking by triple bonds at around $250^{\circ} \mathrm{C}$ while polyimides containing anthracene chromophore ${ }^{16,17}$ did not undergo chemical transformation at this temperature and showed $5 \%$ weight loss in the region of $360-420^{\circ} \mathrm{C}$.
In conclusions, novel polyesters and polyurethanes were synthesized containing 9,10-diethynylanthracene and pyromellitic diimide moieties derived from novel monomer 9,10-bis(4-hydroxy-1-butynyl)anthracene. The polymers were semicrystallines and soluble in common organic solvents and showed strong luminescence with maxima around 480 and $600 \mathrm{~nm}$ for polymers PE1, PE2, PU1, and PE3, PU2. For polymers PE3 and PU2 CTC formation between 9,10-diethynylanthracene and pyromellitic diimide moieties occurs. Bathofluoric shift of the emission maximum for polymers PE3 and PU2 was due to the fact that exited CTC states are responsible for fluorescence. The polymers were electroluminescent. Thus, PE3 showed orange electroluminescence with turnon voltage of $10.5 \mathrm{~V}$ and internal efficiency of $0.002 \%$.

Acknowledgments. This work was supported by the Grant from CONACyT with contract N 4264-E9406. Thanks are also due to Dr. N. Peyghambarian from University of Arizona for electroluminescence measurements, and M. A. Canseco, R. Gabiño, L. Baños, and Carmen Vazquez for assistance in UV spectroscopy, NMR-analysis, X-ray diffractometry, and thermal analysis, respectively.

\section{REFERENCES}

1. S. E. Weber, Chem. Rev., 90, 1469 (1990).

2. M. Fox, W. Jones, and D. Watkins, Chem. Ing. News, 71, 38 (1993).

3. M. Winnik, Acc. Chem. Res., 18, 83 (1985).

4. J. Dajamel A. Yekta, Y. Hu, and M. Winnik, Macromolecules, 25, 7024 (1992)

5. W. Herkstroeter, P. Matric, S. Hartman, J. Willims, and S. Faird, J. Polym. Sci., Polym. Chem. Ed., 21, 2473 (1983).

6. D. Chu and J. Thomas, Macromolecules, 17, 2142 (1984).

7. K. Arora and N. Turro, J. Polym. Sci., Chem. Ed., 25, 259 (1987).

8. T. Stramel, C. Nguyen, S. Webber, and M. Rodgers, J. Phys. Chem., 92, 2934 (1988).

9. T. Cao, P. Munk, C. Ramireddy, Z. Tuzar, and S. Weber, Macromolecules, 23, 4411 (1990).

10. M. Nowakowska, V. Foule, and J. Guillet, J. Am. Chem. Soc., 115, 5975 (1993).

11. S. Fomine, A. Pineda, T. Ogawa, R. Perez, and M. Sotelo, Polym. J., 27, 712 (1995).

12. M. Tlencopatchev, S. Fomine, E. Miranda, L. Fomina, and T. Ogawa, Polym. J., 27, 1173 (1995).

13. S. Fomine, L. Fomina, H. Quiroz, J. M. Mendez, and T. Ogawa, Poiym. J., 27, 1085 (1995).

14. Wachman and C. Frank Polymer, 29, 1191 (1988).

15. C. Simenesci and M. Grigoras, Acad. Repub. Soc. Rom. Met. Sect., 7, 51 (1984).

16. S. Fomine, G. Kapustin, R. Mostovoi, V. Berendiaev, and B. Kotov, Vysokomol. Soedin., Ser. A, 33, 126 (1991).

17. G. Kapustin, V. Tilika, V. Berendiaev, V. Mostovoi, O. Neyland, and B. Kotov, Vysokomol. Soedin., Ser. A., 30, 653 (1988).

18. J. LaFemina, J. Chem. Phys., 90, 5154 (1989).

19. "Organic Syntheses," 2nd ed., John Willey \& Sons, Inc., New York, N.Y., 1961, p 207. 